\title{
Los efectos de las medidas del programa económico del gobierno
}

\author{
Alfonso Goitia
}

\section{Introducción}

El gobierno actual está tratando de impulsar un proyecto neoliberal, el cual se basa en la aplicación de un programa de ajuste estructural y de liberalización de la economia. En este sentido, analizaremos tres aspectos importantes: primero, los problemas fundamentales que enfrenta la economia y sociedad salvadorefia; segundo, las medidas económicas aplicadas; y finalmente, los efectos de estas medidas tanto en el marco de la efectividad para resolver los problemas, como sus efectos negativos sobre los distintos sectores sociales.

\section{Una simplificación de los problemas fundamentales}

La economía y sociedad salvadoreña se debate en la actualidad en una profunda crisis, las causas de ésta se han señalado constantemente como de carácter histórico-estructural, éstas a su vez se vieron agudizadas por el conflicto político-militar.

Identificaremos a partir de esto, tres problemas fundamentales que están presentes en la realidad actual: primero la guerra que ha provocado y sigue provocando altos costos humanos (más de 70.000 muertos a causa del conflicto) y genera grandes distorsiones económicas y nuevos problemas sociales, entre estas distorsiones tenemos los efectos negativos que la guerra genera como son: bajos niveles de producción, mayor déficit fiscal, incremento de costos de producción de las empresas, inflación, deterioro del sector externo, incertidumbre en la inversión, etc. Asimismo, genera también nuevos problemas sociales como: más de medio millón de desplazados, más de 600,000 refu- 
giados, lisiados de guerra, etc. en general, los efectos del conflicto son negativos en muchos aspectos del quehacer nacional.

Un segundo problema es la cada vez mayor pobreza extrema en la que vive o subsisten las grandes mayorias de la población y las graves deficiencias de servicios sociales que éstas demandan solventar. En este sentido, más del $40 \%$ de las familias se debaten en una situación de extrema pobreza, existe un deterioro permanente de la capacidad adquisitiva de los salarios de la población, hay graves deficiencias en las condiciones de salud, educación, vivienda y otros servicios básicos para la población.

Por último tenemos unos profundos desequilibrios macroeconómicos como son: una inflación que el último año alcanzó a $20 \%$ (incremento de precios) y que acumuladamente durante $1980-1988$ supera el $150 \%$; el déficit fiscal que el último año superó los 600 millones de colones y el déficit externo que es superior a los 2.000 millones de colones para este mismo año (1988), además de estar la economía en una fase recesiva, la cual no parece revertirse.

En conjunto estamos ciertamente ante graves problemas económicos y sociales, asi como políticos; esto quiere decir, que la crisis en EI Salvador es integral, lo cual requiere soluciones integrales y no fragmentadas.

\section{Las medidas de ajuste estructural y de liberallzación}

Para enirentar los problemas anteriormente sefialados, el gobierno actual ha asumido la aplicación de una política de ajuste estructural y de liberalización de la economia.

Pero estas medidas esencialmente están orientadas a entrentar los desequilibrios macroeconómicos y especialmente el déficit externo y el déficit fiscal, además de propiciar una reducción de la capacidad reguladora del Estado y en general de la acción económica de éste, dejando al sector empresarial privado ser el "motor" de la economía, supuestamente el que promovería la reactivación y el logro del bienestar social.

Valdria la pena explicar brevemente en que consiste la liberalización y el ajuste estructural y los efectos que supuestamente pueden propiciar. La liberalización significa dejar que las fuerzas del mercado: oferta y demanda, fijen los precios de los bienes y servicios, el precio de la mano de obra (salarios), el precio del dinero y de las divisas. Es decir, la libre competencia determina y regula el funcionamiento de la economía; por lo tanto, se esperaría que estas fuerzas del mercado lo- 
grarían determinar precios adecuados a productores y consumidores, asi como salarios, tasas de interés, tipo de cambio, tarifas, etc., que serian adecuados a todos los interesados, pero en este caso sólo se modifican los precios de productos, tarifas, tipo de cambio y tasas de interés, y el salario se reduce en términos reales.

El ajuste estructural pretende enfrentar los desequilibrios macroeconómicos a través de mecanismos financieros y no reales; es decir, a través de medidas que incidirán sobre un ajuste financiero de los déficit pero no de medidas que incidan sobre el aparato productivo real, o sea sobre modificaciones reales del aparato productivo que permita incrementar la productividad y la producción.

El ajuste estructural persigue como objetivos: promover las exportaciones, mejorar la eficiencia productiva, reducir el tamanio del sector público y una asignación mejor de los recursos productivos; objetivos que, si bien son positivos algunos de ellos, no parecen adecuarse a la realidad económico-social de El Salvador, resultando los efectos de estas medidas muy diferentes a los esperados, según lo que teóricamente se plantea. nerales?

¿Qué efectos podemos esperar de estas medidas en términos ge-

Estas medidas provocarán en general:

\subsection{Un efecto contractlvo de la actividad económica.}

Afectando asi el nivel de empleo; ésto, por que medidas como la modificación en el tipo de cambio, de las tasas de interés y reducción de gasto público, generan una contracción de la actividad económica.

\subsection{Un efecto Inflaclonarlo mayor}

Ya que políticas de liberalización de precios de bienes y servicios, asi como la modificación de tipo de cambio, de las tasas de interés, aumento de impuestos al timbre, elc., provocan un incremento de los precios y por lo tanto afectan la capacidad adquisitiva de la población de ingresos bajos y fijos.

2.3. Tiene un efecto redistrlbutivo a favor del capltal (grandes empresas) y en contra del trabajo (mayorías populares). Porque las medidas disefiadas por los gestores de la política económica tienden a favorecer la acción del gran capital en la economía, propiciándole tipos de cambio favorables a la exportación, trasladan costos de importación mayores a los precios, trasladan los nuevos impuestos indirectos, los impuestos tienen un carácter 
regresivo, la liberalización favorece a pocas empresa que tienen capacidad de control de precios y mercados (estamos ante monopolios privados, oligopólios). En cambio los trabajadores sólo deberán absorber los costos de estas medidas a través de bajos salarios, salarios congelados, mayor incremento de precios de bienes y servicios, difícil acceso al crédito, mayores impuestos indirectos, etc.

En general, el conjunto de medidas que serán aplicadas por el gobiemo favorecerán una ampliación de la enorme deuda social intema que existe con la mayoría de la población (grandes carencias sociales); es decir, estas medidas, en vez de resolver o amortizar la deuda social existente, la profundizarán y agravarán más.

\section{Las medidas económicas y sus efectos}

\subsection{La politica camblarla}

La medida consiste en un tipo de cambio múltiple, donde funciona:

a) Un mercado de tipo de cambio tijo (US\$ $1=\$ 5.00$ ). Aquí se mantienen las exportaciones de café de la cosecha 1988-89 y de otros productos exportables, realizados antes del 25 de julio de 1989, luego pasaría todo al mercado libre. También están los préstamos del sector público, el servicio de la deuda, transferencias y algunas importaciones básicas.

b) El mercado de tipo de cambio libre (bancario). Aquí se desarrollan exportaciones e importaciones no consideradas en el anterior mercado, que son la mayoria.

Los objetlvos de estas medidas son fundamentalmente:

- Incrementar las exportaciones.

- Reducir el déficit externo.

- Mejorar asignación de divisas para importación.

- Aumentar las reservas internacionales netas.

\section{¿Cuales son sus efectos?}

- Contracción de la actividad económica dado que las importaciones aumentan su valor (debido a que la divisa es más cara para el importador).

- Esto provoca a su vez un mayor costo de las importaciones, generando en algunas actividades la incapacidad de asumir estos costos y por lo tanto reducir su capacidad de producción o retirarse 
del mercado, sólo aquellos que puedan asumir estos nuevos costos trasladarán éstos a los precios.

La estructura de competencia no es igual entre las empresas, habrá algunas con capacidad de absorber estos costos mientras otras no podrian.

- Provocan inflación debido a que las empresa que puedan absorber los costos de un mayor valor de las importaciones, lo trasladan a los precios, con sus efectos negativos para los consumidores (los empresarios no asumen parte de los costos, sino que to trasladan todo a los precios).

- El efecto redistributivo es negativo sobre los sectores de bajos ingresos y fijos, dado el mayor nivel de inflación.

- El posible efecto positivo sobre un mayor valor de las exportaciones que se podría haber obtenido, especialmente por las exportaciones de café, se verá reducido debido a la caída de los precios de este producto en el mercado intemacional, mercado sobre el cual no tenemos control o influencia.

La debilidad de nuestras exportaciones está en que los precios, cuotas, etc., son tijados en el mercado externo, por to que difícilmente estas medidas resolverán la debilidad que a nivel externo tenemos.

- Podemos esperar que este año el déficit externo supere al del año pasado, llegando a 500 millones de dólares.

\subsection{Politicas de tasas de Interés}

Las medidas consisten en:

a) Incremento de tasas de interés pasivas

- para depósitos de ahorro aumentan entre $10 \%$ y $13 \%$

- para depósitos a plazo fijo aumentan entre $14.5 \%$ y $18 \%$

b) Incremento de las tasas de interés activas para créditos entre $20 \%$ y $22 \%$.

c) Excepciones

- Créditos ya contratados de micro y pequefia empresa se mantiene tasa actual.

- Créditos de avio agricola contratados cosecha 1989-90.

- Créditos de vivienda hasta $\$ 60.000 .00$ ya contratados, se mantiene tasa de interés. 
- Créditos ya contratados del Fondo de Desarrollo Económico, se mantiene tasa de interés.

d) Nuevos créditos de micro y pequeha empresa, 3 puntos menos que la tasa básica hasta el 31 de julio de 1990; es decir, la tasa de interés para estos nuevos créditos sera de $17 \%$ y antes eran de $9 \%$ a $13 \%$.

e) Créditos del Fondo de Desarrollo Económico aumentarán 3 puntos con ajustes anuales de 3 puntos hasta llegar a $20 \%$. Antes eran de $10 \%$ a $15 \%$.

f) Créditos refinanciamiento ya contratados mantienen sus tasas, es necesario plantear que los que más recurrieron al refinanciamiento a tasas preferenciales fueron los grandes productores (café, algodón, caña de azúcar, etc.) son:

Los objetivos que se persiguen con estas nuevas tasas de interés

- Incrementar el ahorro nacional

- Mejorar la asignación de los recursos financieros

- Lograr una tasa de interés real.

\section{¿Cuáles son los efectos de estas medldas?}

- El aumento de tasas de interés restringe el crédito a los productores, especialmente a los pequeños productores los cuales nuevamente verán afectado su acceso a fuentes de financiamiento formal. Esto puede provocar contracción económica.

- Afectará el acceso a la vivienda, especialmente a los sectores medios ya que la tasa de interés aumentará hasta $22 \%$ y con revisiones periódicas de cada 4 meses, es probable que aumente más.

- Favorecerá a las grandes empresas ya que habrá mayores recursos financieros, si bien a un costo mayor, pero pueden trasladar estos costos a los precios.

- El ahorro no parece que se incremente con mayores tasas de interés para ahorros y depósitos, debido a que serán siempre los mismos sectores los que tendrán capacidad de ahorro. Además, dado que las medidas tienen un efecto inflacionario, harán más difícil el ahorro a los sectores de bajos ingresos, ya que tendrán que utilizar sus ingresos para satisfacer sus necesidades básicas.

- La mejora en la asignación de los recursos financieros será favorable a la gran empresa provocando tendencias hacia la concentración y a 
la desigual competitividad en el mercado entre grandes, medianos y pequenos productores.

- El problema de la asignación de los recursos financieros hacia actividades más productivas no se garantiza con aumentos en la tasa de interés, sino que depende de políticas que definan la orientación del crédito, de la lógica de funcionamiento del sistema bancario (plazos, garantías, orientación preferente, etc.).

\subsection{Politica de llberilzaclón de preclos y tarlfas}

Las medidas consisten:

a) Liberalización de 230 precios de productos agricolas e industriales y control de precios de arroz, malz, frijol, aceite y manteca, harina de trigo, leche IRA y derivados del petróleo.

b) Tarifas de transporte diferenciadas por distancia y calidad del servicio: $\$ 0.40,0.50,0.60$ y 1.00 (Servicio especial).

El aumento oscila entre $33 \%$ y $100 \%$ de la tarifa anterior de $\$ 0.30$.

c) Tarifas eléctricas diferenciadas

Según consumo de energía eléctrica

$40-200 \mathrm{kw}$ incremento $10 \%$ en la tarifa

201 - $500 \mathrm{kw}$ incremento $35 \%$ en la tarifa

501 - más $\mathrm{kw}$ incremento $85 \%$ en la tarifa

Los objetivos de estas medidas son:

- Reducir la inflación

- Estimular la producción y productividad vla mayor competitividad

- Resolver los problemas tinancieros de los empresarios transportistas y de CEL, asl como reducir el subsidio del Estado a estos.

\section{¿Cuáles son los efectos de estas medidas?}

\section{a) La llberación de preclos de blenes}

- Ha generado una mayor inflación, un incremento de precios no solamente de los productos desregulados, sino también de los productos considerados en una canasta básica controlada.

El malz aumentó en $100 \%$ del precio anterior ( 0.35 ctvs - 0.70 )

La leche aumentó en $25 \%$ del precio anterior (\$25 - \$36)

La tortilla aumentó $50 \%$ del precio anterior (0.10 - $0.15 \mathrm{ctvs}$.) 
Así han aumentado también los precios de un conjunto de manufacturas, medicinas, alimentos industriales, etc.

- El efecto inflacionario es negativo para los sectores de bajos ingresos ya que reduce su capacidad adquisitiva y deteriora las condiciones de vida.

- La estructura de mercado que existe en la economía salvadoreña especialmente a nivel de la industria es monopólica u oligopólica, o sea pocas empresas controlan el mercado y pueden fijar precios, por lo tanto la competividad se daria entre estas grandes empresas, desfavoreciendo a pequeños productores.

b) El aumento de tarlfas al transporte tanto urbano como interdepartamental, provocará:

- Debemos considerar que más del $90 \%$ de la población utiliza el bus o microbus para transportarse (encuesta IUDOP). Sólo un $5 \%$ tiene vehículo propio.

Más del $40 \%$ de los que viven en Santa Tecla trabajan en el centro de San Salvador. Igualmente más del $68 \%$ que viven en la Colonia Santa Lucia deben transportarse a trabajar en el centro de San Salvador, 10 mismo que el $66 \%$ que viven en la zona de la colonia Zacamil, el $64 \%$ que vive en San Antonio Abad y el $68 \%$ que vive en la colonia Guadalupe de Soyapango.

Es decir, un porcentaje de más del $60 \%$ de los que trabajan y viven en distintas colonias o zonas del AMSS deben trasladarse largas distancias para trabajar.

Esta población deberá pagar las tarifas más altas (60 centavos) afectando asi su gasto familiar.

Además, tenemos que el gasto en transporte constituye el $3.5 \%$ del gasto familiar mensual, esto significa que los aumentos de tarifas incidirán sobre reducciones en otras áreas del presupuesto familiar (alimentación, salud, etc.).

- La medida no fue consultada con los sectores involucrados, sólo se trató de resolver el problema de los transportistas y del gobierno, pero no el de los usuarios.

- Se ha favorecido al transportista momentáneamente, pero en la medida que la inflación y el nuevo tipo de cambio genere incremento de precios, sus costos nuevamente serán mayores y buscarán nuevas tarifas. 
- El gobierno ha resuelto momentáneamente su problema al eliminar el subsidio a los transportistas, reduciendo asi su gasto, pero cargando el costo sobre los sectores populares.

\section{C) El Incremento de las tarlfas de energla eléctrica}

- Si bien éstas son diferenciadas dependiendo del consumo, por lo tanto hay cierta progresividad de las tarifas, lo cual muestra cierto criterio de equidad; esto no significa que habrá sectores sobre los cuales recaerá con mayor fuerza los efectos de esta medida.

- En este sentido son los sectores medios los que verán impactados relativamente sus ingresos ante las nuevas tarifas.

- Probablemente haya un ahorro de energia, pero el problema fundamental de CEL que es el déficit tinanciero que tiene; es causado tanto por el sabotaje, la guerra, los efectos de los aumentos de tipo de cambio sobre las deudas internacionales contraidas, los costos de reparación, etc. Es decir, no se esta actuando sobre el factor fundamental que genera este déficit de CEL, que es el conflicto armado.

- Por otra parte, no se han modificado las tarifas al sector comercial e industrial bajo el criterio de no incidir negativamente sobre la producción. Pero los pequenos productores que no tienen instalaciones industriales o comerciales trasladarán estos costos a los precios incidiendo así negativamente sobre el consumo popular.

\section{Concluslones}

Sí bien se han considerado aplicar otras medidas como reducir aranceles, reducir el gasto público, homogenizar el pago del impuesto al timbre, modificar la tabla impositiva del impuesto a la renta, eliminar impuestos a la exportación, etc., éstas todavia no han sido aplicadas, pero una vez implementadas la mayoría de ellas seguirán desfavoreciendo a los sectores populares y favoreciendo al capital. Los costos del programa de ajuste recaerán asl sobre los más pobres.

Las medidas económicas aquí analizadas, nos muestran los efectos negativos que tendrán sobre la economia y los sectores populares. Por lo tanto, la economla no se reactivará, ni favorecerá a "los más pobres que son los privilegiados" del nuevo gobierno.

Serán pues, estos sectores de bajos ingresos los que soportarán el peso negativo de las medidas, mientras que los empresarios obtengan mayores ganancias, supuestamente para que en el futuro los flujos del crecimiento se distribuyan más equitativamente. 